\title{
Distribution, abundance, and microhabitat characterization of small juvenile corals at Palmyra Atoll
}

\author{
M. S. Roth ${ }^{1, *}$, N. Knowlton ${ }^{1,2}$ \\ ${ }^{1}$ Center for Marine Biodiversity and Conservation, Scripps Institution of Oceanography, University of California San Diego, \\ 9500 Gilman Drive, La Jolla, California 92093-0208, USA \\ ${ }^{2}$ Department of Invertebrate Zoology, National Museum of Natural History, Smithsonian Institution, MRC 163, \\ PO Box 37012, Washington, DC 20013-7012, USA
}

\begin{abstract}
Juvenile corals are an important component of the population dynamics of corals, but little is known about the ecology and natural history of their early life-history stages. In demographic surveys, small juvenile corals are often grouped with larger and older corals or overlooked entirely due to their small size and cryptic nature. This study describes the distribution, abundance, and microhabitat of small juvenile corals, defined as post-settlement corals $\leq 5 \mathrm{~mm}$ in diameter, at Palmyra Atoll, Central Pacific. A diver-operated pulsating blue light and filter system was used to enhance innate coral fluorescence during daylight to aid in detecting small juvenile corals. Juvenile densities ranged from 0 to $59.5 \mathrm{~m}^{-2}$ and were more than 9 times higher on the fore reef $\left(21.9 \pm 0.8 \mathrm{~m}^{-2}\right)$ than on the back reef $\left(2.4 \pm 0.3 \mathrm{~m}^{-2}\right)$. The highest juvenile densities were observed in the middle of the sampled range at $14 \mathrm{~m}$ depth on the fore reef. Juvenile corals accounted for $>31 \%$ of coral colonies in all habitats and depths, which resulted in positively skewed size-frequency distributions. The microhabitat of juvenile corals on coral rubble was best described as a convex surface covered with crustose coralline algae that lacked another coral within a $20 \mathrm{~mm}$ radius. This study provides basic ecology and natural history information of small juvenile corals and shows the feasibility of surveying corals $\leq 5 \mathrm{~mm}$ in diameter as a method for monitoring coral populations and assessing environmental changes on a coral reef.
\end{abstract}

KEY WORDS: Juvenile corals · Ecology · Distribution · Abundance - Microhabitat · Recruit • Palmyra Atoll

Resale or republication not permitted without written consent of the publisher

\section{INTRODUCTION}

Coral reefs are in a state of global decline because of multiple stressors, including overfishing, poor water quality, and rising concentrations of carbon dioxide (Hughes 1994, Jackson 1997, Pandolfi et al. 2003, Bellwood et al. 2004, Hoegh-Guldberg et al. 2007). Therefore, a better understanding of coral population biology is needed for coral reef assessment and management. Population dynamics and demographic analyses require accurate ecological information about all life-history stages, but little is known about the ecology of small juvenile corals (e.g. $\leq 5 \mathrm{~mm}$ in dia- meter). Small juvenile corals, also termed recruits in some studies, are critical to the future of coral reefs because they become the foundation of a reef ecosystem, and are an important component of resiliency, a reef's ability to recover from disturbance (Bellwood et al. 2004).

Coral population data can be used to assess the health of coral reefs. For example, coral size-frequency distributions are used to infer the future trajectory of coral populations (Bak \& Meesters 1998, 1999, Hughes \& Tanner 2000, Smith et al. 2005). In demographic models, varying recruitment rates can change whether a coral population increases or decreases (Hughes \& 
Tanner 2000, Edmunds \& Elahi 2007). The ecology and population dynamics of early post-settlement corals are poorly understood because of challenges in surveying juvenile corals. Coral recruits are often $\leq 1 \mathrm{~mm}$ (Babcock et al. 2003), making them difficult to detect on a coral reef (Miller et al. 2000). A lack of data on the abundance of juvenile corals can lead to erroneous size-frequency distributions and inaccurate population models.

There are 3 principal reasons why previous juvenile coral studies provide inadequate information on the earliest life-history stage of corals: (1) Many studies defined juvenile corals broadly, grouping small and large juveniles together. In studies that randomly surveyed juvenile coral densities on natural substrates (e.g. Bak \& Engel 1979, Rogers et al. 1984, Edmunds \& Carpenter 2001), the most common definition for a juvenile coral was a coral $\leq 40 \mathrm{~mm}$ in diameter (Fig. 1). Occasionally, size detection limits are reported as low

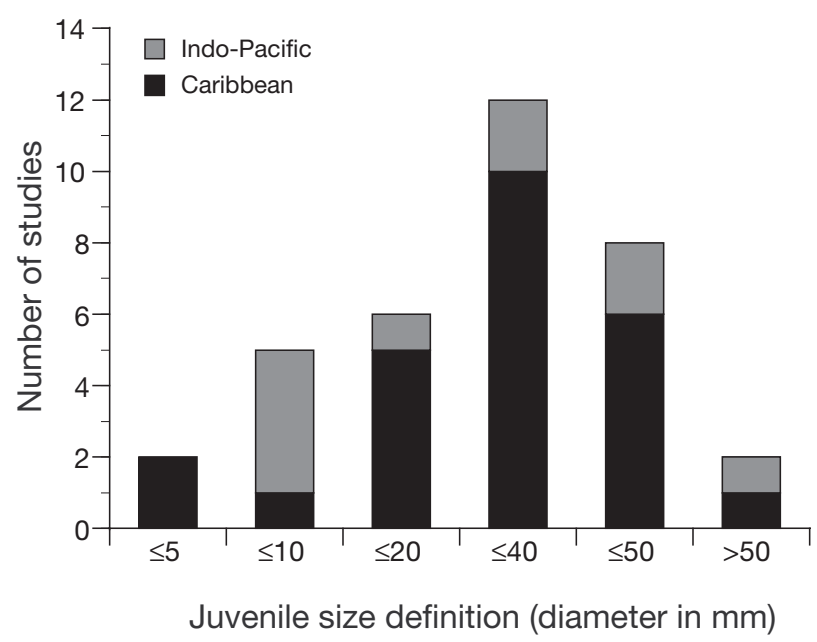

Fig. 1. The smallest juvenile size definition used in previous studies of juvenile coral density on natural substrates $(n=35)$. Studies were conducted in the Caribbean and Indo-Pacific. The definition was given as a diameter in the literature except for Smith (1992). For Smith (1992), the smallest size class $\left(\leq 0.25 \mathrm{~cm}^{2}\right)$ was converted to equivalent spherical diameter of $\leq 5.6 \mathrm{~mm}$, which was placed in $\leq 5 \mathrm{~mm}$ category. (Sources: $\leq 5 \mathrm{~mm}$ : Smith 1992, Mumby 1999; $\leq 10 \mathrm{~mm}$ : Connell 1973, Harriott 1985, Babcock 1991, Hughes \& Tanner 2000, Brown et al. 2002; $\leq 20$ mm: Smith 1997, Kramer 2003, Ruiz-Zarate \& Arias-Gonzalez 2004, Piniak et al. 2005, Smith et al. 2005, Vidal et al. 2005; $\leq 40 \mathrm{~mm}$ : Bak \& Engel 1979, Colgan 1981, Rogers et al. 1984, Wittenberg \& Hunte 1992, Chiappone \& Sullivan 1996, Edmunds \& Bruno 1996, Edmunds 2000, Edmunds \& Carpenter 2001, Edmunds et al. 2004, Carpenter \& Edmunds 2006, Glassom \& Chadwick 2006, Edmunds \& Elahi 2007; $\leq 50$ mm: Rylaarsdam 1983, Bak 1987, Edmunds et al. 1998, van Woesik et al. 1999, Miller et al. 2000, Webster \& Smith 2002, Moulding 2005, Sandin et al. 2008; >50 mm: Dustan 1977, Tamelander 2002) as $5 \mathrm{~mm}$ (Miller et al. 2000) or even $1 \mathrm{~mm}$ (Glassom \& Chadwick 2006), but such small individuals are difficult to detect and are almost certainly underrepresented in these studies, as previously acknowledged (Miller et al. 2000, Glassom \& Chadwick 2006). (2) Artificial substrates such as ceramic tiles are often used to study post-settlement recruits (Hughes et al. 1999, Mundy 2000, Fox 2004). Population dynamics on artificial substrates are substantially different than on natural reef substrates (Rylaarsdam 1983) because artificial substrates often lack appropriate chemical cues from biofilms and/or crustose coralline algae to which juvenile corals respond (Morse \& Morse 1996). Furthermore, mortality on artificial substrates is much higher than on natural substrates (Rylaarsdam 1983). Hence, basic measurements of distribution and abundance on artificial substrates may differ from measurements on natural reef substrates because the population dynamics are likely to be dissimilar between the 2 environments. (3) Most previous studies of juvenile corals have been conducted on degraded coral reefs. Over $70 \%$ of the previous density studies, including the 2 previous studies that included a $\leq 5 \mathrm{~mm}$ size class (Smith 1992, Mumby 1999), were carried out in the Caribbean (Fig. 1), where significant reductions in the abundance of herbivores and carnivores began centuries ago, followed by major losses of architectural species beginning in the 1970s (Jackson 1997, Aronson et al. 2002, Gardner et al. 2003, Pandolfi et al. 2003). Thus, the importance of the present study was to provide ecological data on small juvenile corals on natural substrates of a healthy coral reef, thereby addressing the limitations of previous studies.

The objective of the present study was to characterize the distribution, abundance, and microhabitat of corals $\leq 5 \mathrm{~mm}$ in diameter using a novel modification of fluorescence techniques. Coral fluorescence has been used recently to help observe coral recruits, because both corals and their symbiotic dinoflagellates autofluoresce when excited with specific wavelengths of light. Past studies have shown that nighttime use of fluorescence techniques results in recruits being more easily observed than in traditional daytime searches (Piniak et al. 2005). Nighttime surveys using fluorescence techniques located 20 to $50 \%$ more coral recruits and smaller recruits compared to traditional daytime searches (Baird et al. 2006). However, night diving is logistically more complicated than day diving. The present study modified the fluorescence technique by adding a pulsating excitation light so that small corals would be easily detected during the day.

The present study was conducted at Palmyra Atoll $\left(5^{\circ} 52^{\prime} \mathrm{N}, 162^{\circ} 06^{\prime} \mathrm{W}\right)$, a US territory in the Northern Line Islands, Central Pacific (Fig. 2). Palmyra is characterized as a healthy coral reef community with a com- 
plete food web, a predominance of crustose coralline algae and hard coral cover, and low biomass of fleshy algae (Sandin et al. 2008). There are 36 genera and 176 species of scleractinians found on Palmyra (Maragos et al. 2008b). Because of Palmyra's geographic isolation, restricted human presence, and recent protection by the US Fish and Wildlife Service, many localized sources of anthropogenic stress, such as overfishing, are absent. Despite some physical alterations to the atoll during World War II (Dawson 1959, Maragos et al. 2008a), Palmyra ranks as exceptionally healthy compared to most reefs (Knowlton \& Jackson 2008).

\section{MATERIALS AND METHODS}

Study locations. Palmyra Atoll is exposed to considerable wave action and strong currents. Depending on the positing of the Intertropical Convergence Zone, Palmyra lies within the North Equatorial Current or the North Equatorial Countercurrent (Hamann et al. 2004, Maragos et al. 2008b). The present study included atoll-wide surveys in both the fore reef and the back reef in August and September 2006 (Fig. 2). The fore reef was dominated by Montipora spp., Pocillopora spp., Fungia spp., Pavona spp., and Porites spp., while the back reef was dominated by Montipora spp., Pocillopora spp., Pavona spp., and Acropora spp. (M. S. Roth unpubl. data). Previous studies found 20 and $45 \%$ live coral cover on the fore reef (Sandin et al. 2008 and NOAA data reported therein). Eight fore reef sites were haphazardly chosen to span the north and south sides of the atoll, encompassing all sloping fore reef habitat. Each fore reef site was surveyed at 3 depths: 10,14 , and $18 \mathrm{~m}$. Because of wave exposure, it was not feasible to survey shallower depths on the fore reef, and that area was devoid of corals. The back reef primarily consisted of habitat on the western side of the atoll with 2 shallow pools on the eastern side of the atoll. Sites were haphazardly chosen to span the western side of the atoll, and at sites of interest including the Longline Wreck (Site D, Fig. 2) and the Northeast and Southeast Coral Gardens (Sites G and H, Fig. 2). On the shallow back reef, it was only possible to survey at 1 depth at each site, which varied from 1.5 to $4.9 \mathrm{~m}$.

Detection of juvenile corals using pulsating fluorescence-aided visualization. In the present study, a small juvenile coral was defined as a post-settlement coral with its longest diameter $\leq 5 \mathrm{~mm}$. Hereafter, small juvenile corals are referred to as juvenile corals. Any corals $\leq 40 \mathrm{~mm}$ are most likely to arise from sexual reproduction rather than asexual reproduction (Bak \& Engel 1979) and were easy to distinguish from corals produced through asexual reproduction by growth and morphological characteristics.

When excited with blue light, both corals and their symbiotic dinoflagellates autofluoresce. Coral autofluorescence, which is primarily green but can also be other colors, is due to the presence of fluorescent proteins, while dinoflagellate red autofluorescence is due to chlorophyll. Autofluorescence was detected with a prototype lighting system (NightSea). The light (UK C4) was modified so that both bulbs were fitted with a custom blue interference filter to induce autofluorescence. In an improvement over previous fluorescence methods, one of the bulbs was customized to flash. A diving mask yellow barrier filter, which blocked the excitation light to the viewer, enabled the easy detection of corals including those on all sides of surfaces
Fig. 2. Study sites at Palmyra Atoll $\left(5^{\circ} 52^{\prime} \mathrm{N}, 162^{\circ} 06^{\prime} \mathrm{W}\right)$. Transect and quadrat surveys were conducted at all sites (O), and rubble surveys were conducted on a subset of sites $(\times)$. Fore reef sites are labeled from west to east: (1: Tortugonas, 2: North Beach, 3: Aviation, and 4: Quail on the north side of the atoll, and 5: Penguin Spit, 6: Paradise, 7: North South Causeway, and 8: Southeast Corner on the south side of the atoll). Back reef sites were labeled from north to south: (A: Tortugonas, B: Far North of Longline Wreck, C: North of Longline Wreck, D: Longline Wreck, E: Penguin Spit Permanent, F: Penguin Spit Mid on the west side of the atoll, G: Northeast Coral Gardens, and H: Southeast Coral Gardens on the east side of the atoll)

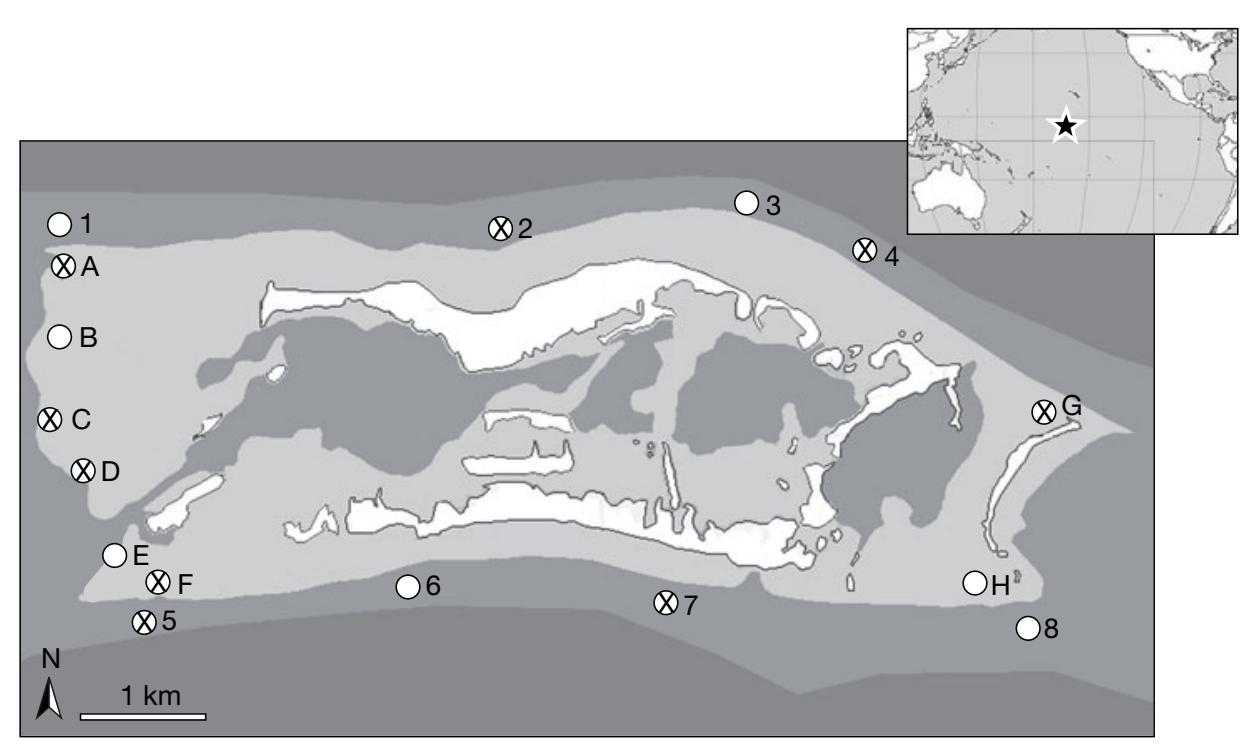


and in crevices. The pulsating excitation light caused corals $<1 \mathrm{~mm}$ in diameter to 'blink' conspicuously, even in daylight. Because other reef organisms fluoresce, it was necessary to discriminate small corals from similar-looking organisms such as anemones and zoanthids, which were soft when probed compared to corals. The only coral species observed without autofluorescence was the azooxanthellate Tubastrea sp.; additionally hydrocorals in the genus Stylaster lacked autofluorescence. There have been observations of non-fluorescent morphs of coral species (Salih et al. 2000, Baird et al. 2006).

Transect and quadrat surveys. The fore reef and back reef of Palmyra Atoll were surveyed using transects and quadrats. Quadrats with a circular area of $0.24 \mathrm{~m}^{2}$ were placed every $5 \mathrm{~m}$ along $50 \mathrm{~m}$ transects of constant depth. All scleractinian corals inside or partially inside a quadrat were counted and binned into size classes using longest diameter as the size criterion. As described in the previous paragraph, a pulsating blue light with a barrier filter was used during the daytime to facilitate detection of the smallest corals. Because the lighting system was intended to enhance detection of juvenile corals, corals were counted whether they were detected under blue light or sunlight. Because it was not possible to taxonomically identify small juvenile corals, surveys represent the whole coral community. At each fore reef site 9 to 11 quadrats were sampled, and 11 quadrats at each back reef site.

Rubble surveys. To determine the microhabitat characteristics of juvenile corals, coral rubble pieces were collected and carefully examined for juvenile corals using white and blue light and a stereomicroscope. Two 5 gallon (19 l) buckets of rubble from the top $\sim 10 \mathrm{~cm}$ of the reef were collected at each site, and the volume of rubble collected determined by water displacement. A subset of back reef and fore reef sites (Fig. 2) were surveyed for logistical reasons. All sides of the rubble were examined but it was not feasible to record the orientation of each piece of rubble. The size of each coral was measured with vernier calipers and the coral microhabitat was described by the surface geometry, substrate material and proximity to other corals. The geometry was defined by the surface plane on which the coral was lying: convex surface, depression (concave surface), hole/crevice (cavity in the surface), or cryptic (other non-exposed surfaces such as between branches). The substrate material was recorded as anything underneath the coral; when a coral was lying on crustose coralline algae and bare space, both were included. A coral was categorized as having a coral neighbor if there was a coral within $20 \mathrm{~mm}$ of its perimeter. The microhabitat characteristics of 2 size classes of corals ( $\leq 1$ and $4-5 \mathrm{~mm}$ ) were compared using the frequency distributions of microhabitat data.

Statistical analyses. Statistical analyses were conducted using JMP version 7.0 and $\mathrm{R}$ software version 2.2.1. A 2-way ANOVA (site and depth) was used to test for differences in juvenile densities on the fore reef. A 1-way ANOVA (site) was used to test for differences in juvenile densities in the back reef. To compare the fore reef and back reef communities, data from fore reef (all depths) and back reef were used in statistical analyses. Unpaired $t$-tests were used to compare fore reef and back reef juvenile densities. Juvenile densities were expressed as mean \pm SE. Sizefrequency histograms were created from ln-transformed data, and compared to normal distributions based on the characteristics of the data using the Kolmogorov-Smirnov test (Bak \& Meesters 1998, 1999). Skewness was calculated from transformed data and its significance was determined by a comparison with the skewness of 10000 replicates of resampling a normal distribution with the same sample size. Pearson's $\chi^{2}$ tests were used to test for differences in microhabitat (geometry and substrate) frequency among juveniles from different depths on the fore reef. Pearson's $\chi^{2}$ test with Yates continuity correction was used to compare juvenile neighbor microhabitat data from different depths on the fore reef. Additionally, Pearson's $\chi^{2}$ test was used to test for differences in microhabitat between $\leq 1$ and $4-5 \mathrm{~mm}$ corals. Back reef juvenile corals in the rubble surveys were not included in statistical analyses because of low sample size. Statistical significance was based on an $\alpha=0.05$ level.

\section{RESULTS}

\section{Coral size-frequency distribution}

Juvenile corals constituted a substantial proportion of the total coral population (Table 1). The proportion of juveniles was much larger on the fore reef $(34.7 \pm$ $0.9 \%)$ than the back reef $(8.6 \pm 0.1 \%)$. The coral population at Palmyra Atoll was dominated by smaller corals (Fig. 3). Logarithmic transformations of neither the fore reef nor the back reef coral population size frequencies were normally distributed $(\mathrm{p}<0.001$ for each); both were significantly right- (positive) skewed, with skewness values of $+1.22(\mathrm{p}<0.001)$ and +0.72 $(p<0.001)$, respectively. On the fore reef, the size distribution was significantly right-skewed at each depth examined: $+1.13(\mathrm{p}<0.001)$ at $10 \mathrm{~m},+1.29(\mathrm{p}<0.001)$ at $14 \mathrm{~m}$, and $+1.21(\mathrm{p}<0.001)$ at $18 \mathrm{~m}$. These results indicate that each habitat contained more small corals than would be predicted by a normal distribution (Fig. 3). 
Table 1. Juvenile coral ( $\leq 5 \mathrm{~mm})$ density and percentage of total corals. N: number of quadrats. Data are mean \pm SE

\begin{tabular}{|lrrc|}
\hline Habitat & $\mathrm{N}$ & Density $\left(\mathrm{m}^{-2}\right)$ & \% of total corals \\
\hline 10 $\mathrm{m}$ fore reef & 86 & $17.05 \pm 1.06$ & $33.7 \pm 0.7$ \\
14 $\mathrm{m}$ fore reef & 82 & $30.13 \pm 1.64$ & $36.7 \pm 0.6$ \\
18 $\mathrm{m}$ fore reef & 78 & $18.60 \pm 1.10$ & $32.6 \pm 0.7$ \\
Total fore reef & 246 & $21.90 \pm 0.77$ & $34.7 \pm 0.9$ \\
Back reef & 88 & $2.41 \pm 0.30$ & $8.6 \pm 0.1$ \\
Total & 334 & $16.77 \pm 0.61$ & $31.1 \pm 0.3$ \\
\hline
\end{tabular}

\section{Juvenile coral distribution and abundance}

In the transect and quadrat surveys, a total of 1338 juvenile corals were counted in $80.16 \mathrm{~m}^{2}$ reef sampled. Average juvenile density on the fore reef was over 9 times higher and statistically different than the back reef $\left(t_{332}=7.4, \mathrm{p}<0.001\right.$; Table 1$)$. On the fore reef, both depth $\left(F_{2,222}=7.4, \mathrm{p}<0.001\right)$ and site $\left(F_{7,222}=4.4\right.$, $\mathrm{p}<0.001$ ) had a significant effect on the juvenile density, but the interaction between depth and site was not significant $\left(F_{14,222}=1.2, \mathrm{p}=0.26\right.$; Fig. 4A). Average density was highest at mid-depths $(14 \mathrm{~m})$, with shallower $(10 \mathrm{~m})$ and deeper $(18 \mathrm{~m})$ depths having densities of 43 and $38 \%$ respectively of densities observed at mid-depths. The highest recorded juvenile density was $59.5 \pm 8.3 \mathrm{~m}^{-2}$ at Site 5 (Penguin Spit) at a depth of $14 \mathrm{~m}$. The southern sites (Sites 5 to 8, Fig. 2) had higher densities of juvenile corals that were significantly different from the northern sites (Sites 1 to $4 ; t_{244}=2.8, \mathrm{p}<$ 0.01 ), but there was no difference in densities between western (Sites 1, 2, 5, and 6) and eastern sites (Sites 3, 4,7 , and $8 ; t_{244}=-0.6, p=0.52$ ). On the back reef, there were 2 sites without juvenile corals. There were no sig-

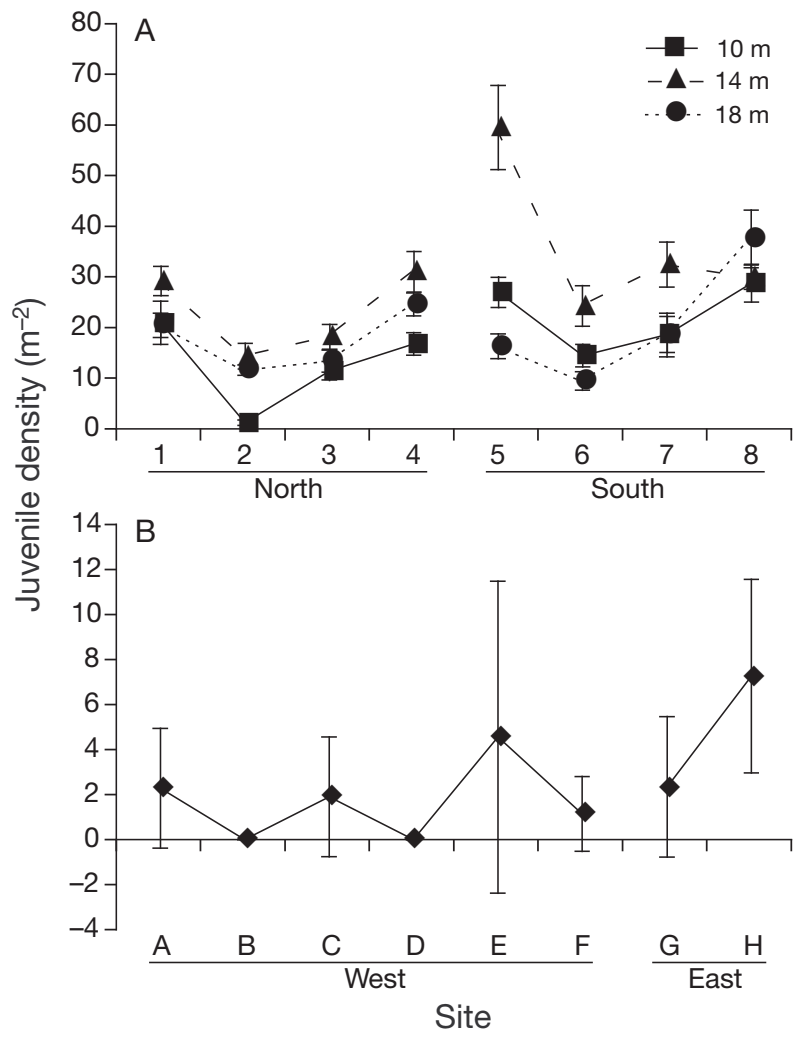

Fig. 4. Juvenile coral ( $\leq 5 \mathrm{~mm}$ in diameter) densities at the (A) fore reef by depth and site and (B) back reef by site. Data are mean \pm SE. See Fig. 2 legend for site codes

nificant differences in juvenile densities among back reef sites $\left(F_{7,80}=2.1, \mathrm{p}=0.05\right.$; Fig. $\left.4 \mathrm{~B}\right)$.

The coral rubble surveys showed similar juvenile distribution and abundance patterns to the transect and quadrat surveys. We sampled $114 \mathrm{l}$ of coral rubble
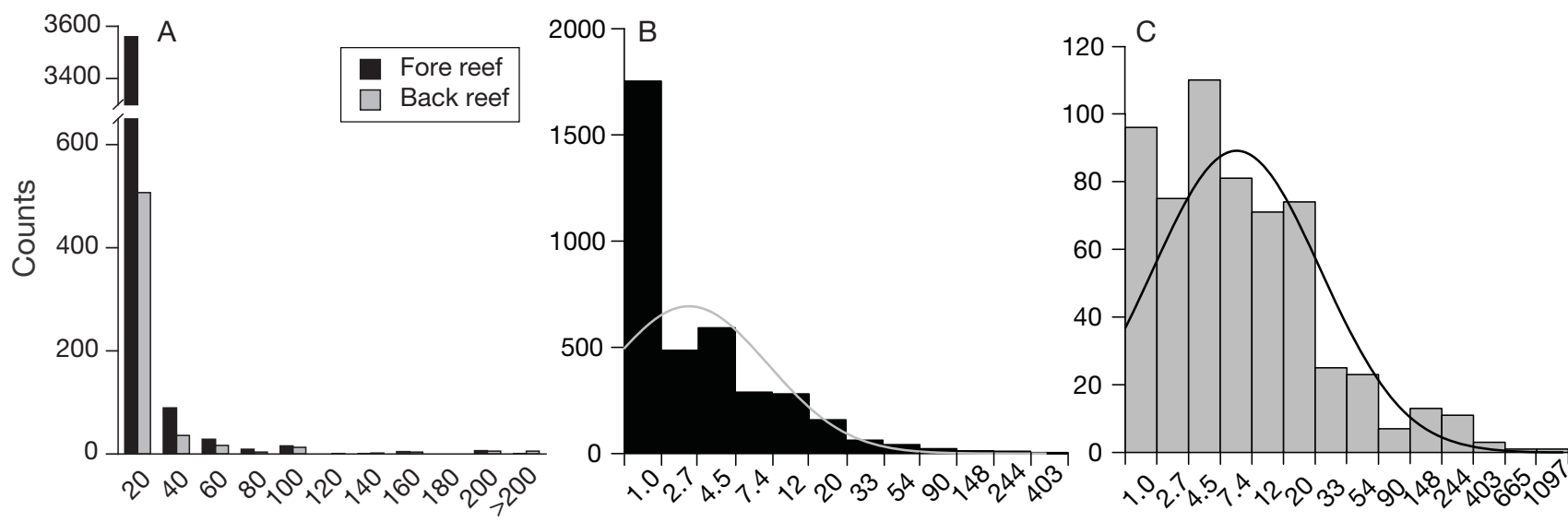

Size $(\mathrm{cm})$

Fig. 3. Size distribution of corals. (A) Untransformed size-frequency distribution on the fore reef $(n=3713)$ and the back reef $(n=$ 591). Size-frequency distribution of logarithmically transformed data on (B) the fore reef and (C) the back reef. In (B) and (C), the curve represents the normal distribution. Coral distributions were significantly right-skewed $(p<0.001)$ and significantly different from the normal distribution $(\mathrm{p}<0.001$ for each). Labels on the $x$-axis were represented by their endpoints (e.g. 20 represents $0-20$ and 40 represents $20.01-40)$ 
from 4 fore reef sites and 5 back reef sites. On the fore reef, most juvenile corals $(45.7 \%)$ were found at the mid-depth of $14 \mathrm{~m}$, followed by $18 \mathrm{~m} \mathrm{(40.9 \% )} \mathrm{and} 10 \mathrm{~m}$ $(13.4 \%)$. As with the density data, more juveniles were observed in the fore reef rubble $(n=314)$ than the back reef rubble $(\mathrm{n}=8)$.

\section{Juvenile coral microhabitat}

Based on microhabitat analysis of 314 juvenile corals obtained from the fore reef coral rubble, most juvenile corals were found on convex surfaces, rather than in depressions, holes/crevices, or other cryptic locations (Fig. 5A), a pattern that was not affected by depth $\left(\chi^{2}=\right.$ $6.7, \mathrm{p}=0.35)$. Corals were predominately located on crustose coralline algae, followed by bare space at all depths (Fig. 5B). Surprisingly, $>12 \%$ of corals were found on the brown encrusting alga Lobophora sp. The substrate characteristic patterns were not significantly different between samples collected from 14 and $18 \mathrm{~m}$ $\left(\chi^{2}=3.0, p=0.38\right)$. These patterns were generally similar to substrate characteristics from corals collected from $10 \mathrm{~m}$, but the crustose coralline algae microhabitat was less dominant $\left(\chi^{2}=24.2, \mathrm{p}<0.001\right)$. Just under

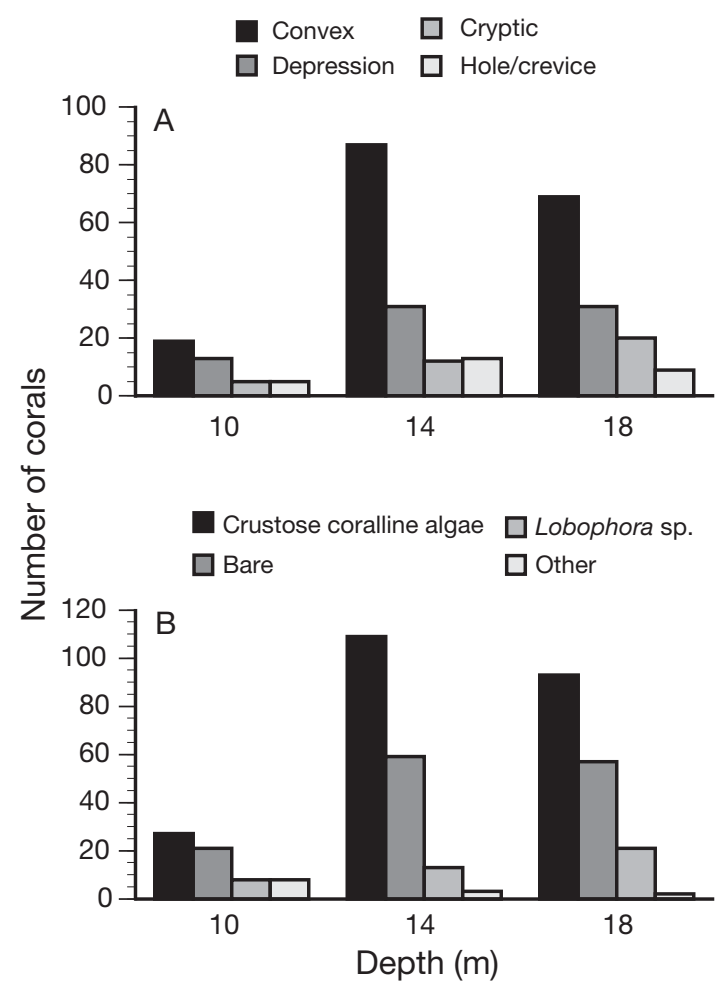

Fig. 5. Microhabitat characteristics, (A) geometry and (B) substrate, of juvenile corals ( $\leq 5 \mathrm{~mm}$ in diameter) on coral rubble from the fore reef. See 'Materials and methods' for description of surface geometry half $(48 \%)$ of the corals had a coral neighbor within a $20 \mathrm{~mm}$ radius.

The microhabitats of corals $\leq 1$ and $4-5 \mathrm{~mm}$ were not statistically different. The ratio of substrate geometries (convex:depression:hole/crevice:other cryptic) for $\leq 1 \mathrm{~mm}$ corals was 41:21:10:11 and for 4-5 mm corals was 42:11:8:5 $\left(\chi^{2}=3.7, p=0.29\right)$. The distribution of substrates (crustose coralline algae:bare:Lobophora sp.: other) for $\leq 1 \mathrm{~mm}$ corals was 58:32:10:2 and for 4-5 mm corals was 48:34:10:6 $\left(\chi^{2}=2.9, \mathrm{p}=0.40\right)$. The distribution of neighbors (with:without) for $\leq 1 \mathrm{~mm}$ corals was $37: 46$ and for 4-5 mm corals was 29:36 $\left(\chi^{2}=0.03, p=0.87\right)$.

Too few juveniles were found on the back reef for statistical analyses of their microhabitat characteristics. Qualitatively, back reef juvenile corals appeared to have similar microhabitat distributions as fore reef corals.

\section{DISCUSSION}

The present study used a modified fluorescence technique to make extensive daytime observations of juvenile corals. The equipment required was low-tech, easy to use while SCUBA diving, and affordable for scientists and managers. Coral species that have nonfluorescent morphs may be more difficult to detect and could be underrepresented in these surveys. However, this methodology significantly enhanced the ability to detect small corals that are otherwise difficult to observe and enabled a thorough investigation of the distribution, abundance, and microhabitat of small corals.

The microhabitat data confirmed what is well known - that juvenile corals prefer crustose coralline algae and bare space (Morse \& Morse 1996, Harrington et al. 2004) — but provided some surprising results. Most intriguing was that Lobophora sp. was chosen as a substrate for coral settlement and that large $(4-5 \mathrm{~mm})$ and small juveniles $(\leq 1 \mathrm{~mm})$ had similar distributions in this regard. This suggests that Lobophora sp. did not affect juvenile survivorship at these size classes, perhaps questioning the negative effects of macroalgae on juvenile corals on some reefs. Evidence of these negative effects includes macroalgae decreasing juvenile coral settlement, growth rates, and survivorship in some species (Lirman 2001, Birrell et al. 2005, Box \& Mumby 2007). However, neither settlement rates nor survivorship of coral larvae from Favia fragrum were negatively affected by settling on the green alga Halimeda opuntia, nor was development of the recruits affected over 5 d (Nugues \& Szmant 2006). It is likely that the competition between coral and algae could be affected by nutrients and herbivory (Jompa \& McCook 2002). 
In contradiction to what was anticipated, the distribution of microhabitat substrates was identical between $\leq 1$ and $4-5 \mathrm{~mm}$ corals. These results may challenge previous assumptions of the effects of microhabitat on recruit survivorship (Caley et al. 1996), including geometry (Sammarco 1980), substrate (Harrington et al. 2004), and competition (Sammarco 1991). Other studies have also reported a lack of strong correlation between microhabitat (orientation of substrate) and survivorship in the Caribbean (Edmunds et al. 2004) and on the Great Barrier Reef (Babcock \& Mundy 1996), despite selection for particular microhabitats.

Juvenile coral $(\leq 5 \mathrm{~mm})$ densities on the fore reef at Palmyra Atoll were highest at mid-depths of $14 \mathrm{~m}$, possibly representing a balance between considerable wave exposure at shallower depths and less solar irradiance at deeper depths. Palmyra receives different currents depending on the time of year (Hamann et al. 2004, Maragos et al. 2008b), which may have contributed to a more homogeneous environment. Studies on small-scale flow around Palmyra during coral spawning times could elucidate the spatial patterns of coral recruitment, particularly because coral recruitment can vary considerably in space and time (Hughes et al. 1999). The much lower densities on the back reef compared to the fore reef may have resulted from differences in biological communities or environmental conditions including human alterations to the hydrodynamics due to prior construction during World War II (Dawson 1959, Maragos et al. 2008a).

The 2 other studies of juvenile corals $\leq 5 \mathrm{~mm}$, which were conducted in the Caribbean (Fig. 1), reported lower densities than those observed on the reefs of Palmyra Atoll (Smith 1992, Mumby 1999). Smith (1992) recorded juvenile densities up to $\sim 24 \mathrm{~m}^{-2}$ in Bermuda (data estimated from size-class distribution in Smith 1992, their Fig. 2); Mumby (1999) reported juvenile densities up to $\sim 0.6 \mathrm{~m}^{-2}$ in Belize, compared to $59.5 \mathrm{~m}^{-2}$ in the present study. The disparity in juvenile densities between the present study and these 2 previous studies could have many causes, including the state of reef degradation surveyed, the equipment used to detect juvenile corals, and the ocean basin.

To compare juvenile density estimates with previous studies that have defined juvenile corals as $\leq 40 \mathrm{~mm}$ in diameter, results were re-calculated using the same size class. At Palmyra, densities of corals $\leq 40 \mathrm{~mm}$ on the back reef $\left(13.4 \pm 1.1 \mathrm{~m}^{-2}\right)$ and fore reef $(50.7 \pm$ $\left.1.3 \mathrm{~m}^{-2}\right)$ were significantly different $\left(t_{332}=7.7, \mathrm{p}<\right.$ 0.0001; Fig. 6). Corals $\leq 5 \mathrm{~mm}$ in diameter represent nearly $20 \%$ and over $40 \%$ of the juveniles ( $\leq 40 \mathrm{~mm}$ ) on the back reef and fore reef, respectively. The densities of juveniles $(\leq 40 \mathrm{~mm})$ on the fore reef of Palmyra (41.5 to $67.0 \mathrm{~m}^{-2}$ ) were among the highest recorded in the literature (Table 2). Another study that reported high

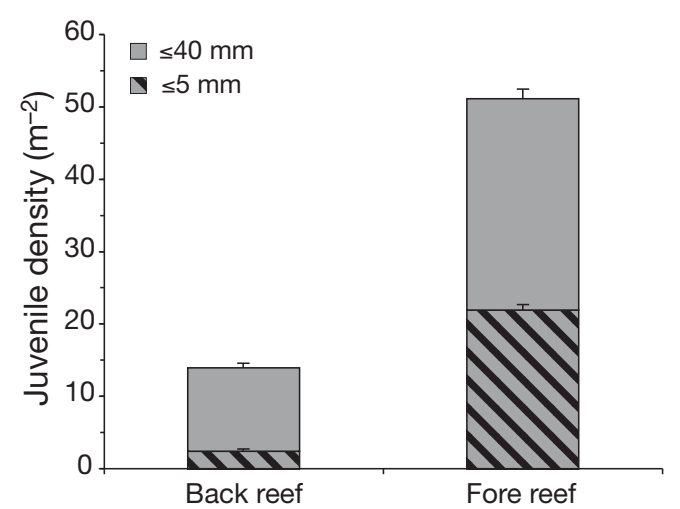

Fig. 6. Densities of juvenile corals using size criteria $\leq 40 \mathrm{~mm}$ and $\leq 5 \mathrm{~mm}$. Data are mean $\pm \mathrm{SE}$

densities of juvenile corals (42 to $173 \mathrm{~m}^{-2}$ ) at sites selected with medium-to-low adult coral cover was in the Red Sea (Glassom \& Chadwick 2006). Interestingly, the proportion of juvenile corals to the total coral population was $\sim 10$ to $27 \%$, similar to that of the present study.

Juvenile corals accounted for a substantial proportion of the coral population; corals on the fore reef $\leq 5 \mathrm{~mm}$ in diameter represented over one-third of all corals. Correspondingly, size-frequency distributions from these data provide a perspective on what a healthy coral reef atoll may look like when all corals including the smallest size classes are surveyed. The size frequencies have a significant positive skewness, indicating a high proportion of small corals, which was also found during a recent study at Palmyra Atoll (Sandin et al. 2008). Surveys of healthy and degraded reefs in the Line Archipelago showed the same patterns in size-frequency distributions of corals (Sandin et al. 2008). However, the most degraded reef had fewer corals in the smallest size class and zero corals in the largest size class, but these distinctions were not captured in the size-frequency distribution analyses.

However, positive skewness of size distributions can be difficult to interpret. It may reflect a high proportion of juvenile corals, which is likely to be an important component of coral reef health, but it could also represent a declining population. Mortality and partial mortality of corals caused by disease, bleaching, or predation reduces colony size and causes fission of large corals. Positive skewing of coral populations in degraded habitats has been reported in the Caribbean (Hughes \& Tanner 2000, Edmunds \& Elahi 2007) and in the Indian Ocean (McClanahan et al. 2008), and predicted from Acanthaster planci predation disturbance models of the eastern Pacific (Fong \& Glynn 1998). In contrast, Bak \& Meesters $(1998,1999)$ proposed that a negatively skewed size-frequency distribution mod- 
Table 2. Comparative table of mean juvenile coral densities using the standard definition of juvenile corals of $\leq 40 \mathrm{~mm}$ in diameter (in descending order of density). C. = central, USVI = US Virgin Islands, W. = western

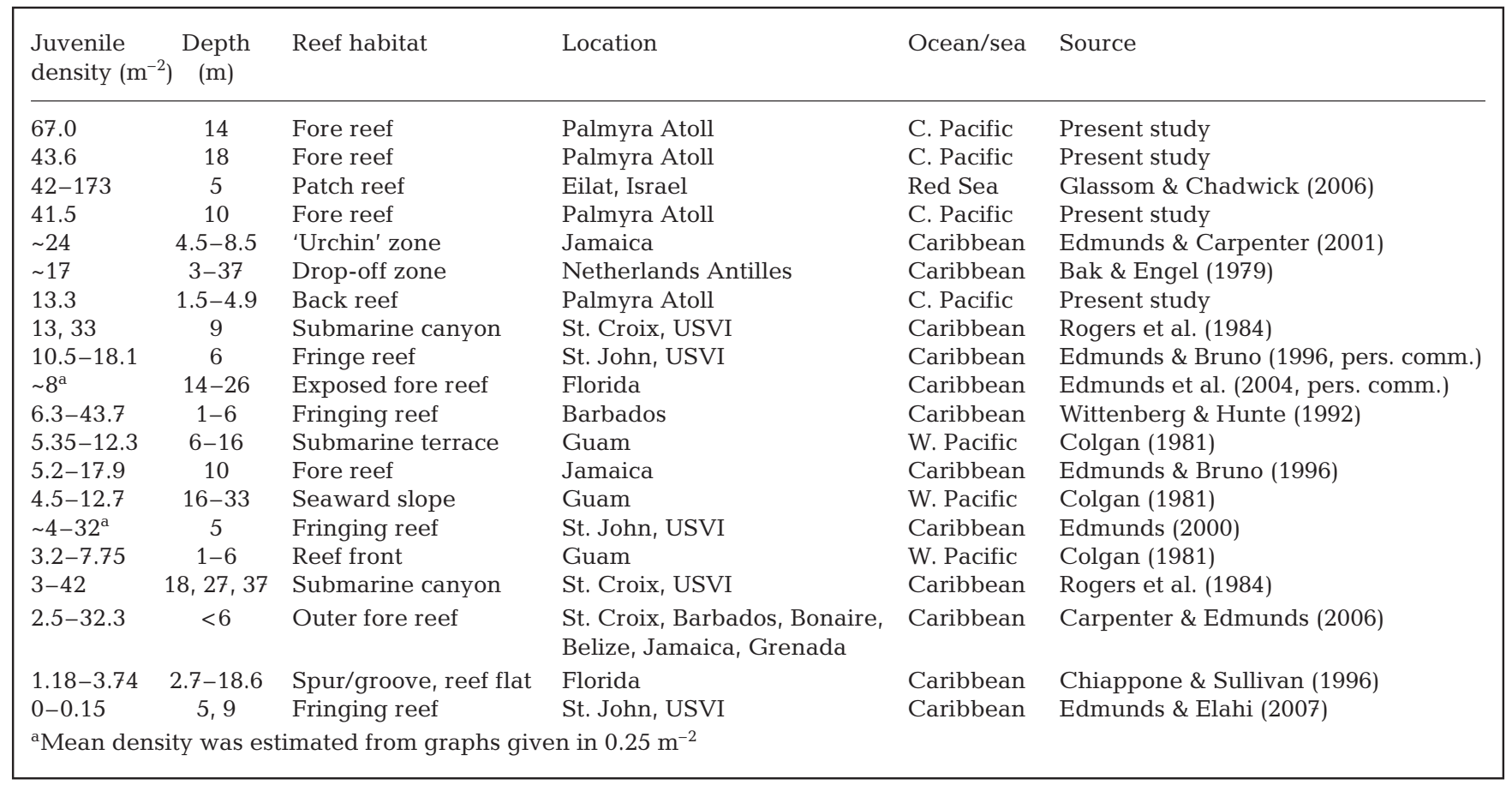

eled by a log-normal distribution inferred an unhealthy coral population. They hypothesized that disturbances increased mortality of smaller colonies and coupled with recruitment failure resulted in the predominance of larger colonies. Positively skewed sizefrequency distributions were observed in the present study because we surveyed a healthy coral reef using a novel method to aid in detecting small juveniles. These data suggest that healthy reefs may be positively skewed, and with degradation become normally distributed and with further degradation become negatively skewed.

Because changes in coral size-frequency distributions can result from multiple factors, purely examining relative size frequencies to infer status of a coral population can be misleading. We suggest that, in addition to relative size-frequency data, it is important to compare the absolute numbers in each size class with particular attention to the smallest and the largest size class of corals. In addition, distinguishing recent settlers from the small remains of once-large colonies can help determine the processes underlying the size patterns observed.

Juvenile coral investigations not only provide relevant ecological data for coral population dynamics, but also could be useful as an indicator of environmental changes. Size-frequency distributions could be particularly relevant for coral reefs that do not have a wellestablished baseline of coral populations, yet still pro- vide insight into a reef's resiliency and its future. A standardized procedure for surveying juvenile corals is needed so that data between locations will be comparable (Abelson \& Gaines 2005). Daytime coral fluorescence surveys are effective, technologically simple, and affordable, providing a new capability for investigations of coral reef biology. Using fluorescence to aid finding juvenile corals should be part of the standardized technique to ensure reliable data on the smallest life-history stage.

Acknowledgements. This research was conducted with support and approval from the US Fish and Wildlife Service and The Nature Conservancy. This research was supported by the Scripps Institution of Oceanography's John Dove Isaacs Professorship of Natural Philosophy (N.K.), a National Science Foundation Interdisciplinary Graduate Education Research Training Fellowship (M.S.R.), and a National Science Foundation Graduate Research Fellowship (M.S.R.). The authors thank J. E. Maragos, T. Konotchick, C. H. Mazel, C. L. Huffard, H. Hamilton, S. A. Sandin, J. E. Smith, and C. McDonald for help in the field or with field equipment, C. N. K. Anderson and K. J. Osborn for help with data analyses and/or figures, and K. L. Marhaver, M. I. Latz, and anonymous reviewers for helpful comments on the manuscript.

\section{LITERATURE CITED}

Abelson A, Gaines S (2005) A call for a standardized protocol of coral recruitment research and outlines for its conception. Mar Pollut Bull 50:1745-1748 
Aronson RB, Macintyre IG, Precht WF, Murdoch TJT, Wapnick CM (2002) The expanding scale of species turnover events on coral reefs in Belize. Ecol Monogr 72:233-249

Babcock R (1991) Comparative demography of three species of scleractinian corals using age- and size-dependent classifications. Ecol Monogr 61:225-244

Babcock R, Mundy C (1996) Coral recruitment: consequences of settlement choice for early growth and survivorship in two scleractinians. J Exp Mar Biol Ecol 206:179-201

Babcock RC, Baird AH, Piromvaragorn S, Thomson DP, Willis BL (2003) Identification of scleractinian coral recruits from Indo-Pacific reefs. Zool Stud 42:211-226

Baird AH, Salih A, Trevor-Jones A (2006) Fluorescence census techniques for the early detection of coral recruits. Coral Reefs 25:73-76

Bak RPM (1987) Effects of chronic oil pollution on a Caribbean coral reef. Mar Pollut Bull 18:534-539

Bak RPM, Engel MS (1979) Distribution, abundance and survival of juvenile hermatypic corals (Scleractinia) and the importance of life history strategies in the parent coral community. Mar Biol 54:341-352

Bak RPM, Meesters EH (1998) Coral population structure: the hidden information of colony size-frequency distributions. Mar Ecol Prog Ser 162:301-306

Bak RPM, Meesters EH (1999) Population structure as a response of coral communities to global change. Am Zool 39:56-65

Bellwood DR, Hughes TP, Folke C, Nystrom M (2004) Confronting the coral reef crisis. Nature 429:827-833

Birrell CL, McCook LJ, Willis BL (2005) Effects of algal turfs and sediment on coral settlement. Mar Pollut Bull 51: 408-414

Box SJ, Mumby PJ (2007) Effect of macroalgal competition on growth and survival of juvenile Caribbean corals. Mar Ecol Prog Ser 342:139-149

Brown BE, Clarke KR, Warwick RM (2002) Serial patterns of biodiversity change in corals across shallow reef flats in Ko Phuket, Thailand, due to the effects of local (sedimentation) and regional (climatic) perturbations. Mar Biol 141: 21-29

> Caley MJ, Carr MH, Hixon MA, Hughes TP, Jones GP, Menge BA (1996) Recruitment and the local dynamics of open marine populations. Annu Rev Ecol Syst 27:477-500

Carpenter RC, Edmunds PJ (2006) Local and regional scale recovery of Diadema promotes recruitment of scleractinian corals. Ecol Lett 9:268-277

Chiappone M, Sullivan KM (1996) Distribution, abundance and species composition of juvenile scleractinian corals in the Florida Reef Tract. Bull Mar Sci 58:555-569

Colgan MW (1981) Long-term recovery process of a coral community after catastrophic disturbance. Technical Report 76. University of Guam Marine Laboratory, Mangilao

Connell JH (1973) Population ecology of reef-building corals. In: Jones OA, Endean R (eds) Biology and geology of coral reefs, Vol 2: Biology 1. Academic Press, New York, p 205-245

Dawson EY (1959) Changes in Palmyra Atoll and its vegetation through the activities of man 1913-1958. Pac Naturalist 1:3-51

Dustan P (1977) Vitality of reef coral populations off Key Largo, Florida: recruitment and mortality. Environ Geol 2: 51-58

- Edmunds PJ (2000) Patterns in the distribution of juvenile corals and coral reef community structure in St. John, US Virgin Islands. Mar Ecol Prog Ser 202:113-124

Edmunds PJ, Bruno JF (1996) The importance of sampling scale in ecology: kilometer-wide variation in coral reef communities. Mar Ecol Prog Ser 143:165-171

Edmunds PJ, Carpenter RC (2001) Recovery of Diadema antillarum reduces macroalgal cover and increases abundance of juvenile corals on a Caribbean reef. Proc Natl Acad Sci USA 98:5067-5071

Edmunds PJ, Elahi R (2007) The demographics of a 15-year decline in cover of the Caribbean reef coral Montastraea annularis. Ecol Monogr 77:3-18

Edmunds PJ, Aronson RB, Swanson DW, Levitan DR, Precht WF (1998) Photographic versus visual census techniques for the quantification of juvenile corals. Bull Mar Sci 62: 937-946

> Edmunds PJ, Bruno JF, Carlon DB (2004) Effects of depth and microhabitat on growth and survivorship of juvenile corals in the Florida Keys. Mar Ecol Prog Ser 278:115-124

Fong P, Glynn PW (1998) A dynamic size-structured population model: Does disturbance control size structure of a population of the massive coral Gardineroseris planulata in the Eastern Pacific? Mar Biol 130:663-674

> Fox HE (2004) Coral recruitment in blasted and unblasted sites in Indonesia: assessing rehabilitation potential. Mar Ecol Prog Ser 269:131-139

Gardner TA, Cote IM, Gill JA, Grant A, Watkinson AR (2003) Long-term region-wide declines in Caribbean corals. Science 301:958-960

> Glassom D, Chadwick NE (2006) Recruitment, growth and mortality of juvenile corals at Eilat, northern Red Sea. Mar Ecol Prog Ser 318:111-122

Hamann IM, Boehlert GW, Wilson CD (2004) Effects of steep topography on the flow and stratification near Palmyra Atoll. Ocean Dyn 54:460-473

Harrington L, Fabricius K, De'Ath G, Negri A (2004) Recognition and selection of settlement substrata determine postsettlement survival in corals. Ecology 85:3428-3437

Harriott VJ (1985) Recruitment patterns of scleractinian corals at Lizard Island, Great Barrier Reef. Proc 5th Int Coral Reef Symp, Tahiti 4:367-372

> Hoegh-Guldberg O, Mumby PJ, Hooten AJ, Steneck RS and others (2007) Coral reefs under rapid climate change and ocean acidification. Science 318:1737-1742

Hughes TP (1994) Catastrophes, phase shifts, and large-scale degradation of a Caribbean coral reef. Science 265: 1547-1551

Hughes TP, Tanner JE (2000) Recruitment failure, life histories, and long-term decline of Caribbean corals. Ecology 81:2250-2263

> Hughes TP, Baird AH, Dinsdale EA, Moltschaniwskyj NA, Pratchett MS, Tanner JE, Willis BL (1999) Patterns of recruitment and abundance of corals along the Great Barrier Reef. Nature 397:59-63

> Jackson JBC (1997) Reefs since Columbus. Coral Reefs 16: S23-S32

Jompa J, McCook LJ (2002) Effects of competition and herbivory on interactions between a hard coral and a brown alga. J Exp Mar Biol Ecol 271:25-39

> Knowlton N, Jackson JBC (2008) Shifting baselines, local impacts, and global change on coral reefs. PLoS Biol 6:e54

Kramer PA (2003) Synthesis of coral reef health indicators for the Western Atlantic: results of the AGRRA Program (1997-2000). Atoll Res Bull 496:1-57

Lirman D (2001) Competition between macroalgae and corals: effects of herbivore exclusion and increased algal biomass on coral survivorship and growth. Coral Reefs 19:392-399

Maragos J, Friedlander AM, Godwin S, Musburger C and others (2008a) U.S. coral reefs in the Line and Phoenix 
Islands, central Pacific Ocean: status, threats, and significance. In: Riegl B, Dodge RE (eds) Coral reefs of the USA. Springer, Dordecht, p 643-689

Maragos J, Miller J, Gove J, DeMartini E and others (2008b) U.S. coral reefs in the Line and Phoenix Islands, central Pacific Ocean: history, geology, oceanography, and biology. In: Riegl B, Dodge RE (eds) Coral reefs of the USA. Springer, Dordecht, p 595-642

McClanahan TR, Ateweberhan M, Omukoto J (2008) Longterm changes in coral colony size distributions on Kenyan reefs under different management regimes and across the 1998 bleaching event. Mar Biol 153:755-768

Miller MW, Weil E, Szmant AM (2000) Coral recruitment and juvenile mortality as structuring factors for reef benthic communities in Biscayne National Park, USA. Coral Reefs 19:115-123

Morse ANC, Morse DE (1996) Flypapers for coral and other planktonic larvae. Bioscience 46:254-262

Moulding AL (2005) Coral recruitment patterns in the Florida Keys. Rev Biol Trop 53:75-82

Mumby PJ (1999) Bleaching and hurricane disturbances to populations of coral recruits in Belize. Mar Ecol Prog Ser 190:27-35

Mundy CN (2000) An appraisal of methods used in coral recruitment studies. Coral Reefs 19:124-131

Nugues MM, Szmant AM (2006) Coral settlement onto Halimeda opuntia: a fatal attraction to an ephemeral substrate? Coral Reefs 25:585-591

Pandolfi JM, Bradbury RH, Sala E, Hughes TP and others (2003) Global trajectories of the long-term decline of coral reef ecosystems. Science 301:955-958

Piniak GA, Fogarty ND, Addison CM, Kenworthy WJ (2005) Fluorescence census techniques for coral recruits. Coral Reefs 24:496-500

Rogers CS, Fitz HC, Gilnack M, Beets J, Hardin J (1984) Scleractinian coral recruitment patterns at Salt River submarine canyon, St. Croix, United States Virgin Islands. Coral Reefs 3:69-76

Ruiz-Zarate MA, Arias-Gonzalez JE (2004) Spatial study of juvenile corals in the northern region of the Mesoamerican Barrier Reef System (MBRS). Coral Reefs 23:584-594

Editorial responsibility: Charles Birkeland, Honolulu, Hawaii, USA
Rylaarsdam KW (1983) Life histories and abundance patterns of colonial corals on Jamaican reefs. Mar Ecol Prog Ser 13: $249-260$

Salih A, Larkum A, Cox G, Kuhl M, Hoegh-Guldberg O (2000) Fluorescent pigments in corals are photoprotective. Nature 408:850-853

> Sammarco PW (1980) Diadema and its relationship to coral spat mortality: grazing, competition, and biological disturbance. J Exp Mar Biol Ecol 45:245-272

Sammarco PW (1991) Geographically specific recruitment and post-settlement mortality as influences on coral communities: the cross-continental shelf transplant experiment. Limnol Oceanogr 36:496-514

Sandin SA, Smith JE, DeMartini EE, Dinsdale EA and others (2008) Baselines and degradation of coral reefs in the Northern Line Islands. PLoS One 3:e1548

Smith LD, Devlin M, Haynes D, Gilmour JP (2005) A demographic approach to monitoring the health of coral reefs. Mar Pollut Bull 51:399-407

Smith SR (1992) Patterns of coral recruitment and post-settlement mortality on Bermuda's reefs: comparisons to Caribbean and Pacific Reefs. Am Zool 32:663-673

Smith SR (1997) Patterns of coral settlement, recruitment and juvenile mortality with depth at Conch Reef, Florida. Proc 8th Int Coral Reef Symp, Panama 2:1197-1202

Tamelander J (2002) Coral recruitment following a mass mortality event. Ambio 31:551-557

van Woesik R, Tomascik T, Blake S (1999) Coral assemblages and physico-chemical characteristics of the Whitsunday Islands: evidence of recent community changes. Mar Freshw Res 50:427-440

Vidal AM, Villamil CM, Acosta A (2005) Composition and density of juvenile corals at two deep reefs in San Andres Island, Colombian Caribbean. Bol Invest Mar Cost 34: 211-225

Webster G, Smith SR (2002) Reduced juvenile coral populations on reefs affected by sewage discharge in Bermuda. Proc 9th Int Coral Reef Symp, Bali 2:1041-1046

Wittenberg M, Hunte W (1992) Effects of eutrophication and sedimentation on juvenile corals. I. Abundance, mortality and community structure. Mar Biol 112:131-138

Submitted: May 19, 2008; Accepted: October 20, 2008

Proofs received from author(s): February 3, 2009 